GU J Sci, Part C, 6(3): 492-506 (2018)

Gazi Üniversitesi
Fen Bilimleri Dergisi
PART C: TASARIM VE TEKNOLOJI
dergipark.gov.tr/http-gujsc-gazi-edu-tr

\title{
Su Alma Ağzı Giriş Şeklinin Hava Girişli Çevrinti Üzerindeki Ölçek Etkisi
}

\author{
Kerem TAŞTAN ${ }^{1, *}$, Nevzat YILDIRIM ${ }^{2}$ \\ ${ }^{I}$ Gazi Üniversitesi, Mühendislik Fakültesi, İnşaat Mühendisliği Bölümü, 06570, Maltepe/ANKARA \\ ${ }^{2}$ Çankaya Üniversitesi, Mühendislik Fakültesi, İnşaat Mühendisliği Bölümü, 06790, Etimesgut/ANKARA
}

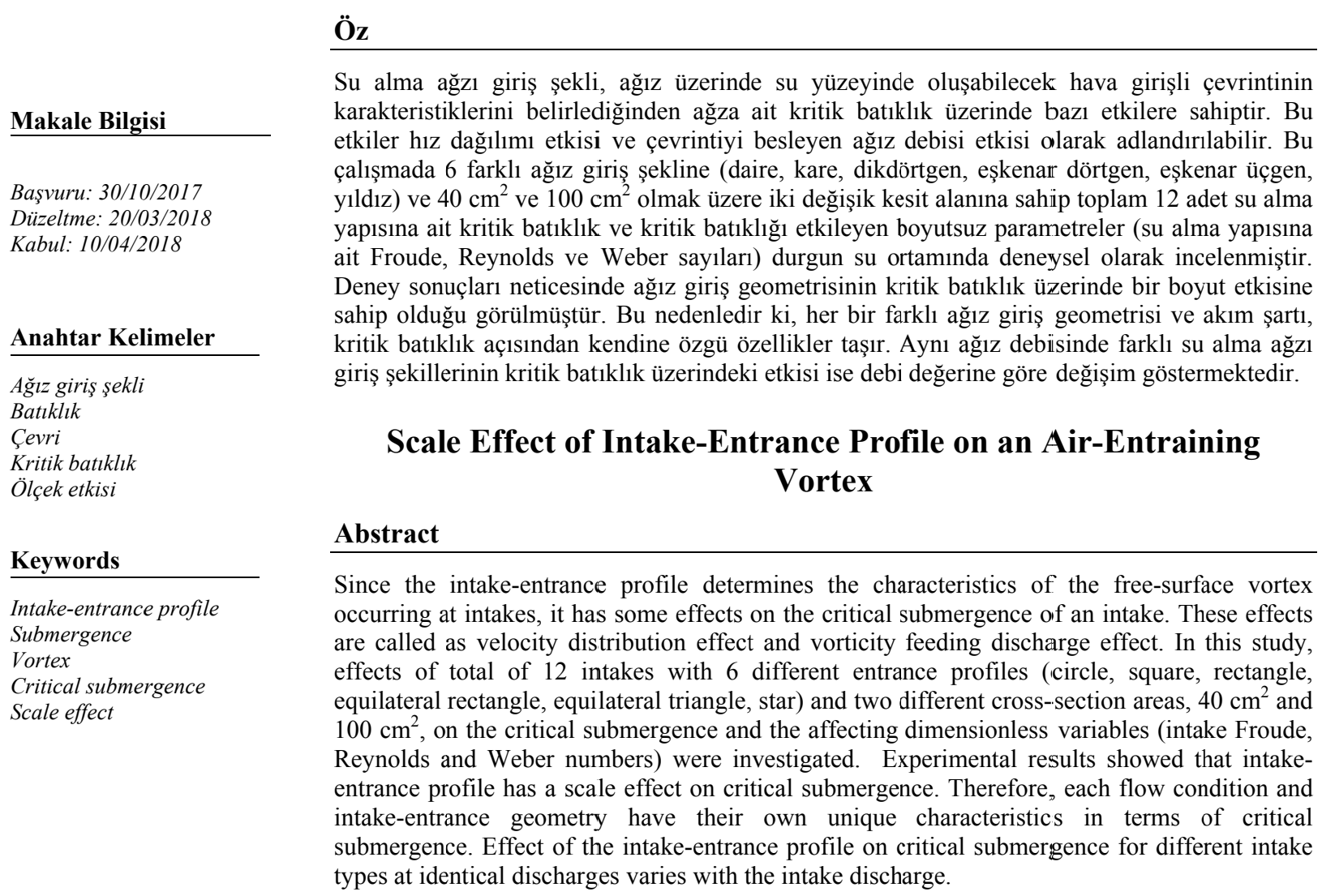

\section{GİRIŞ (INTRODUCTION)}

İçme, sanayi, enerji üretimi ve sulama gibi çeşitli ihtiyaçları karşılamak için gereken su; nehir, dere, göl veya deniz gibi ortamlardan su alma ağızları vasıtasıyla alınır. Su alma ağzının su yüzeyinden olan düşey mesafesine "batıklık $(S)$ " denir. Su alma ağzına ait batıklık yeterli değilse ağza hava girişi olur. Hava girişinin başladığı andaki batıklığa da (hava girişli serbest çevrintinin en alt ucunun ağız seviyesine ulaştığı durumdaki batıklığa) "kritik batıklık $\left(S_{c}\right)$ " denir (Şekil 1). Kritik batıklıktan küçük batıklıklarda ağza devamlı hava girerek ağızdan yeterli debi alınamamasına, pompa, türbin veya su iletim hattındaki diğer elemanlarda kavitasyon ve titreşim oluşumuna sebep olur. 


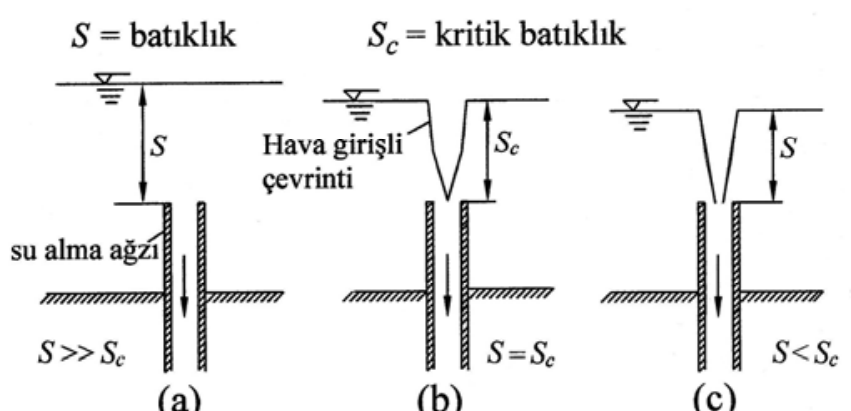

(a)

(b)

(c)

Şekil 1. Bir su alma ăgzındaki akım: (a) Hava girişi yok; (b) Hava girişli çevrintinin alt ucu su alma ăgzına ulaşıyor (kritik durum); (c) Ağza devamlı hava girişi var

Hidrolik mühendisleri hava girişli çevrinti üzerinde ağız giriş şekillerinin ve boyutsuz değişkenlerin (su alma yapısına ait Froude, Reynolds ve Weber sayıları) etkilerini ve model ile prototip arasındaki benzeşim şartlarını sıklıkla tartışmaktadırlar. Önceki çalışmalar Froude veya Reynolds benzeşimine göre inşa edilen modellerin kritik batıklık açısından tam olarak benzeşimi sağlamadığını göstermiştir. $\mathrm{Bu}$ durum "boyut etkisi" veya "ölçek etkisi" (scale effect) veya "Froude, Reynolds ve Weber sayılarının etkisi" olarak adlandırılabilir. Günümüzde literatürde boyutsuz değişkenlerin farklı giriş şekillerine sahip su alma ağızlarına ait kritik batıklık üzerindeki ölçek etkisini inceleyen bir çalışmaya rastlanmamıştır. Bu çalışmada 6 farklı şekle (daire, kare, dikdörtgen, eşkenar dörtgen, eşkenar üçgen, yıldız); $40 \mathrm{~cm}^{2}$ ve 100 $\mathrm{cm}^{2}$ olmak üzere iki değişik kesit alanına sahip toplam 12 adet su alma ağzına ait kritik batıklık ve kritik batıklığı etkileyen boyutsuz parametreler durgun su ortamında deneysel olarak incelenmiştir.

\section{2. ÖNCEKİ ÇALIŞMALAR (PREVIOUS STUDIES)}

Daggett ve Keulegan [1] silindirik bir su tankının tabanına yerleştirilen dairesel bir orifise, serbest çevri yoluyla hava girişi üzerinde viskozite, yüzeysel gerilme ve akıma dışardan uygulanan çevrintinin etkilerini araştırmışlardır. Su alma yapısına ait Reynolds sayısının (Reynolds sayısı $=\mathrm{R}_{\mathrm{e}}=V D / v$; burada $V=$ su alma yapısındaki ortalama akım hızı, $D=$ su alma yapısının iç çapı, $v=$ sıvının kinematik viskozitesidir) $5 \times 10^{4}$ den büyük olması durumunda ağza ait debi katsayısının sadece çevrinti sayısına bağlı olduğunu göstermişlerdir. Jain ve ark. [2] silindirik bir tankın tabanına yerleştirdikleri su alma ağzına ait kritik batıklık üzerinde yaptıkları deneylerde, su alma yapısına ait Reynolds sayısının $2,5 \times 10^{3}$ ile $6,5 \times 10^{5}$ arasinda, Weber sayisinın ise $1,2 \times 10^{2}$ ile $3,4 \times 10^{4}$ (Weber sayıs $=\mathrm{W}=\rho V^{2} \mathrm{D} / \sigma$; burada $\rho=$ sıvının yoğunluğu, $\sigma=$ sıvının yüzeysel gerilmesidir) arasında olduğunda bu sayıların kritik batıklık üzerinde etkilerinin ihmal edilebileceğini göstermişlerdir. Model ve prototip arasında geometrik benzerlik sağlandığında, dinamik benzerliğin de Froude sayılarının eşitliği ile sağlanması gerektiğini, fakat viskozite etkisinin de göz önüne alınması için bir düzeltme faktörü kullanılması gerektiğini belirtmişlerdir. Anwar ve Amphlett [3] düzgün dairesel kesitli giriş ağzı ile çan şeklinde giriş ağzının kritik batıklık açısından bir fark yaratmadığını ifade etmişlerdir. Hecker [4] su alma yapısına ait Froude sayısının [Froude sayısı $=\mathrm{F}=V /(g D)^{0.5}$; burada $g=$ yerçekimi ivmesidir] benzerliğine dayanan modellerde bir miktar ölçek etkisinin var olduğu bu yüzden model değerleri bulunurken Froude sayısının arttırılması gerektiğini ifade etmiştir. Model ve prototip arasında hız eşitliğine dayanan modellerin ancak büyük modellerde uygun olabileceği sonucuna varmıştır. Yıldırım ve Kocabaş [5] üniform akım ortamında bulunan düşey aşağı su alan bir su alma ağzına ait kritik batıklığı bulmak için potansiyel akım yaklaşımını kullanmışlardır. Bu araştırmacılar su alma ağzına ait kritik batıklığın, ağız ile aynı merkez ve debiye sahip hayali "kritik küresel kuyu yüzeyinin (KKKY)" yarıçapına eşit olduğunu göstermişlerdir [6]. Yıldırım ve Kocabaş [7] üniform akım için geliştirilen KKKY kavramının durgun su ortamından su alan ağızlar için de kullanılabileceğini göstermişlerdir. Yıldırım ve ark. [8,9] düşey aşağı ve ölü son duvarından yatay olarak su alan ağızlar üzerinde yaptıkları deneylerde akım sınırları ve ağız borusunun kritik batıklık üzerindeki engel etkilerini incelemişlerdir. Yıldırım [10] dikdörtgen kanal akımı içerisine yerleştirilmiş düşey aşağı ve ölü son duvarından yatay olarak su alan dikdörtgen kesitli bir su alma ağzına ait kritik batıklığı potansiyel akım çözümüyle bulmuştur. Ancak yapılan çalışmada boyut etkisi veya su alma yapısına ait Froude, Reynolds ve Weber sayılarının etkileri incelenmemiş olup bulunan neticeler 
başka ağız giriş şekilleriyle kıyaslanmamıştır. Yıldırım ve Taştan [11] kanal akımı içerisine yerleştirilmiş düşey aşağı ve ölü son duvarından yatay olarak su alan su alma ağızlarının kritik batıklı̆̆ üzerinde akım sınır etkilerini deneysel olarak karşılaştırmışlardır [12]. Taştan ve Yıldırım [13] boyutsuz parametrelerin düşey aşağı su alan dairesel su alma ağzına ait kritik batıklık üzerindeki etkisi üzerine çalışmışlardır. Suerich-Gulick ve ark. [14] ölü son duvarından yatay olarak su alan bir su alma ağzı için yaklaşım akımının ve ağız geometrisinin su alma ağızlarında oluşan çevrintinin karakteristikleri üzerindeki etkisini incelemek için yarı ampirik bir model önermişlerdir. Taştan ve Yıldırım [15] düşey aşağı su alan dairesel kesitli su alma ağzına ait kritik batıklık üzerinde Froude, Reynolds ve Weber sayılarının etkilerini araştırmışlardır. Model ile prototip arasında kritik batıklık açısından benzeşim için kinematik benzeşimin sağlanmasının yeterli olduğunu göstermişlerdir. Taştan [16] düşey aşağı ve ölü son duvarından yatay olarak su alan dairesel su alma ağızları için kritik batıklık üzerinde boyut ve akım sınır etkilerini araştırmıştır. Eroğlu ve Bahadırlı [17], Yıldırım [10]'ın dikdörtgen ağızlara ait kritik batıklığın hesaplanması için potansiyel akım yaklaşımı neticesinde bulduğu kritik küresel kuyu yüzeyinin yarıçapını, akım ortamında oluşan Rankine şeklinin duraklama noktasının ağza mesafesine eşit kabul eden başka bir kritik küresel kuyu yüzeyi kullanarak hesaplamışlardır. Taştan [18], kanal akımı içerisine yerleştirilmiş tek ve ikili dikdörtgen su alma ağızlarına ait kritik batıklı̆̆ deneysel ve teorik olarak incelemiştir. Yang ve ark. [19] ağız giriş şekillerinin kritik batıklık üzerindeki etkilerini incelemişlerdir. Çalışmalarında su alma yapısına ait Froude sayısı aralığ $10,25-0,65$ olup farklı ağız giriş şekillerinin olası boyut etkileri de araştırılmamıştır.

Mevcut çalışmalardaki eksikler ve bu çalışmada nelerin yapıldığı aşağıda özetlenmiştir.

i) Mevcut çalışmaların çoğunluğunda su alma ağzı olarak dairesel borular kullanılmış olup diğer ağız giriş şekillerinin kritik batıklık üzerindeki etkileri yeterince incelenmemiştir. Dairesel giriş ağzı dışında farklı giriş ağız şekillerini inceleyen çalışmalar arasında Yıldırım [10], Eroğlu ve Bahadırlı [17], Taştan [18] ve Yang ve ark. [19] gösterilebilir. Ancak bu çalışmalarda da boyut etkisi veya su alma yapısına ait Froude, Reynolds ve Weber sayılarının etkileri incelenmemiş, bulunan neticeler başka ağız giriş şekilleriyle kıyaslanmamıştır.

ii) Mevcut çalışmalarda kullanılan ağızlara ait Froude sayısı aralı̆̆ Froude sayılarına ait deney verisi yeterli değildir. Yüksek Froude sayılarında kritik batıklık ile Froude sayısı arasındaki ilişki, düşük Froude sayılarına göre farklı olduğu gösterildiğinden yüksek Froude sayılarına ait deney verileri ilerideki yapılacak çalışmalar için de değerlidir. Bu çalışmada hidrolik yarıçap esaslı Froude sayısının en büyük değeri 5,7 olup farklı su alma ağız giriş şekillerinin incelendiği çalışmalarda böyle bir değere ulaşılamadığ 1 görülmüsştür [Bu değer ve bu değerden daha büyük Froude sayısı değerleri bazı araştırmacıların (Denny [20], $D=10,16 \mathrm{~cm}-20,23 \mathrm{~cm}$ ve $\mathrm{F}=$ $0,49$ - 6,04; Jain [21], $D=1,15 \mathrm{~cm}-7,46 \mathrm{~cm}$ ve $\mathrm{F}=1,25-20)$ model deneylerinde de gözükmektedir. Fakat bu deneylerin sadece dairesel su alma ağızları ile yapıldığı unutulmamalıdır].

iii) Farklı su alma ağzı giriş şekilleri üzerinde ölçek veya boyut etkisinin (scale effect) incelendiği başka bir çalışmaya rastlanmamıştır.

\section{BOYUT ANALIZİ (DIMENSIONAL ANALYSIS)}

Dairesel kesitli silindirik bir tankın merkezine yerleştirilmiş herhangi bir giriş kesitine sahip düşey aşağ su alan bir su alma ağzı ele alınsın (Şekil 2).

Su alma ağzına ait kritik batıklık $\left(S_{c}\right)$ ile etkileyen değişkenler arasındaki fonksiyonel ilişki aşağıdaki gibi yazılabilir.

$S_{c}=\mathrm{f}_{1}\left(V, \rho, v, \Gamma, \sigma, g, R_{h}, c, b\right)$

Burada; $V=$ su alma yapısındaki ortalama akım hızı, $\rho=$ akışkanın yoğunluğu, $v=$ akışkanın kinematik viskozitesi, $\Gamma=$ akıma dışarıda uygulanan çevrinti, $\sigma=$ akışkanın yüzey gerilmesi, $g=$ yerçekimi ivmesi, $b=$ su alma ağzının silindir tankın yanal duvarına olan mesafesi ve $c=$ su alma ağzı merkeziyle silindir tankin tabanı arasındaki mesafedir. 


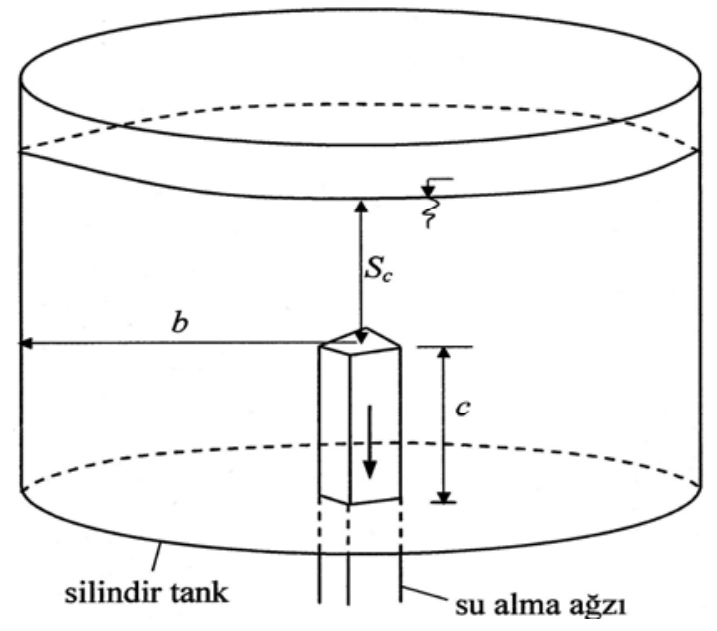

Şekil 2. Su alma ağzl ve silindir tank içerisindeki yerleşimine ait büyüklükler

$\mathrm{Bu}$ çalışmada hidrolik yarıçap $\left(R_{h}\right)$ hesaplanırken ıslak çevre yerine akımın ağza girebildiği çevre (AAGÇ) terimi kullanılmıştır. Çünkü bazı durumlarda ağzın tüm çevresi akım girişine müsaade etmeyecek şekilde konumlanmış olabilir. Fakat mevcut çalışmada ağzın tüm çevresi boyunca ağza akım girebildiği için "AAGÇ" ile sslak çevre aynıdır $\left(R_{h}=A\right.$ /AAGÇ, $A=$ su alma ağzı girişine ait iç kesit alanı). Bu değişkenlere boyut analizi uygulandığında aşağıdaki eşitlik elde edilir.

$\frac{S_{c}}{4 R_{h}}=f_{2}\left(\frac{c}{4 R_{h}}, \frac{b}{4 R_{h}}, \mathrm{~F}, \mathrm{~K}, \mathrm{R}_{\mathrm{e}}, \mathrm{W}\right)$

Bu eşitlikte;

$\mathrm{F}=\frac{V}{\sqrt{g 4 R_{h}}}=$ su alma yapısina ait Froude sayıs

$\mathrm{K}=\frac{\Gamma}{V 4 R_{h}}=$ çevrinti sayıs 1

$\mathrm{R}_{\mathrm{e}}=\frac{V 4 R_{h}}{v}=$ su alma yapısına ait Reynolds sayıs 1

$\mathrm{W}=\frac{\rho 4 R_{h} V^{2}}{\sigma}=$ su alma yapısına ait Weber sayısı

Yukarıdaki boyutsuz parametrelerin tanımı yapılırken $R_{h}$ yerine $4 R_{h}$ kullanılmasının nedeni, dairesel kesitli bir boru için boru iç çapının hidrolik yarıçapın 4 katı olduğu bilgisi ile benzerlik oluşturulmak istenmesinden dolayıdır. İstenirse $4 R_{h}$ yerine $R_{h}$ ' da kullanılabilir; elde edilecek değerler bu tanımlamaya göre değişeceğinden herhangi bir davranış farkı olmayacaktır.

Yapılan deneylerde sadece su alma yapısına ait boyutsuz parametrelerin $\left(F, R_{e}, W\right)$ kritik batıklık üzerindeki etkilerini incelemek amacıyla, su alma ağzının silindir tankın yan duvarlarına ve tabanına olan mesafeleri en büyük (maksimum) kritik batıklıktan daha büyük tutulmuştur [8,9]. Dolayısıyla Eş. 2.'deki $b /\left(4 R_{h}\right)$ ve $c /\left(4 R_{h}\right)$ büyüklüklerinin kritik batıklık üzerindeki etkileri ihmal edilebileceğinden eşitlikten çıkartılabilir. Akıma dışardan herhangi bir çevri uygulanmadığından $(\Gamma=0, \mathrm{~K}=0) \mathrm{K}$ terimi de ihmal edilebilir. Bu kabullerden sonra Eş. 2. aşağıdaki gibi yazılabilir.

$$
\frac{S_{c}}{4 R_{h}}=f_{3}\left(\mathrm{~F}, \mathrm{R}_{\mathrm{e}}, \mathrm{W}\right)
$$

Eş. 4.’teki ilişkiyi incelemek ve bir önceki bölümde belirtilen mevcut çalışmalardaki eksikleri gidermek için aşağıda anlatılan deneyler yapılmıştır. 


\section{DENEYLER VE DENEY DÜZENEĞİ (EXPERIMENTS AND EXPERIMENTAL SET-UP)}

Deneylerde iç çap1 2,5 m, yüksekliği $1,2 \mathrm{~m}$ ve üretildiği sacın kalınlığg $3,5 \mathrm{~mm}$ olan silindir bir tank kullanılmıştır (Şekil 3). Su alma ağzı tank tabanında $1,90 \mathrm{~m}$ çapında ve $0,20 \mathrm{~m}$ yüksekliğinde yapılmış beton silindirik döşemenin içerisinden geçerek pompaya bağlanmıştır. Pompa 7,5 kW gücünde olup suyunu debi ölçümünün yapıldığı üçgen savağa verir.

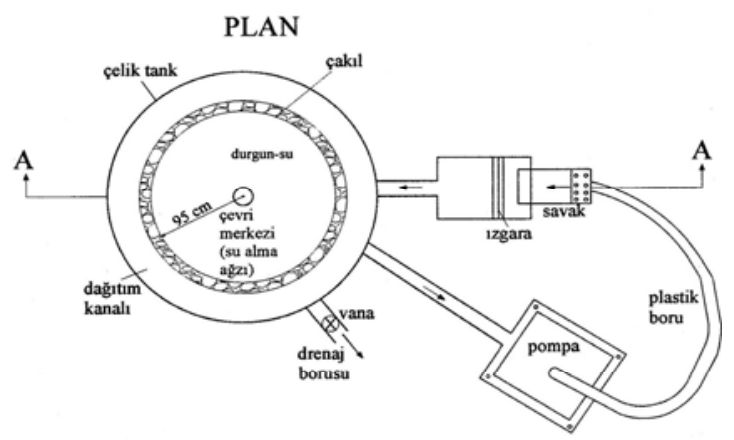

A-A KESİTİ

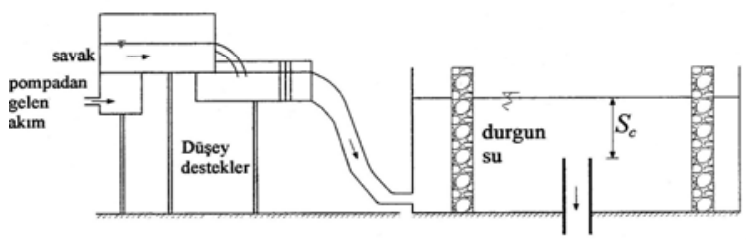

Şekil 3. Deney düzeneği (ölçeksiz)
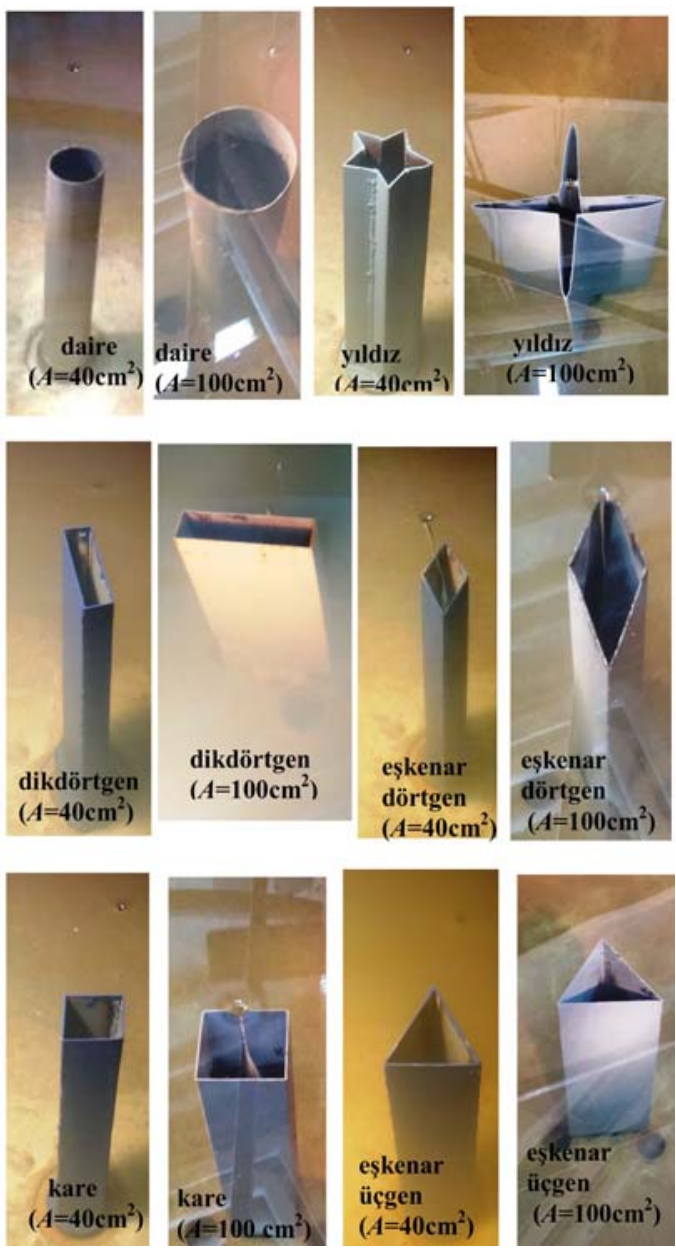

Şekil 4. Deneylerde kullanılan su alma ă̆ızlarına ait fotoğraflar 
Ağızdan alınan debinin devir-daiminin sağlanması için savaktan çıkan su tekrar tanka verilir. Savaktan tekrar tanka verilen akımın enerjisini kırarak akımda sebep olacağı düzensizlikleri yok etmek için de 15 cm kalınlığında çakı1 filttre kullanılmıştır. Söz konusu filtre, beton döşemenin dış kısmı ile tankın iç yüzü arasına düşey demir çubuklarla ve dairesel yatay demir çubuklarla inşa edilmiş eş merkezli iki kafesin her ikisine de yerleştirilen delikli ızgaraların arasına ince çakıl doldurularak elde edilmiştir [22]. Deneylerde Şekil 4 ve 5'te gösterildiği gibi iç kesit alanı $40 \mathrm{~cm}^{2}$ ve $100 \mathrm{~cm}^{2}$ olan iki grup halinde 6 farklı su alma ağz1 kullanılmıştır (daire, kare, yıldız, dikdörtgen, eşkenar dörtgen ve eşkenar üçgen). Su alma ağızları $2 \mathrm{~mm}$ et kalınlığına sahip saclardan üretilmiştir.
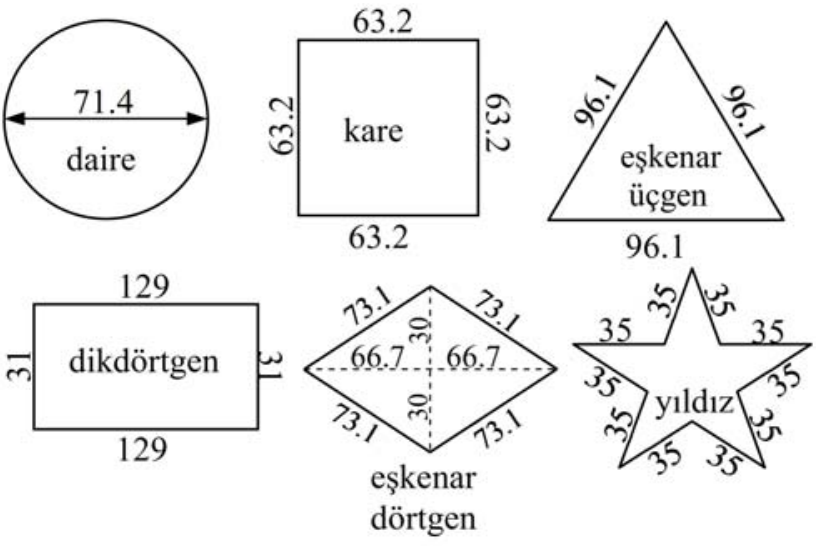

(a)
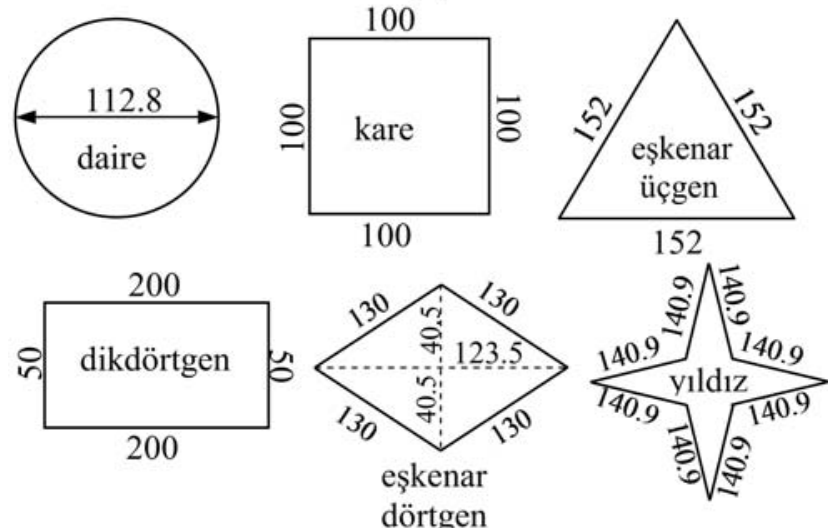

dörtgen

(b)

Şekil 5. Su alma ăğı girişs şekilleri: a) $A=40 \mathrm{~cm}^{2}$, b) $A=100 \mathrm{~cm}^{2}$ (Tüm ölçüler mm cinsindendir)

Hava girişli çevrinti veya kritik batıklık üzerinde herhangi bir engel etkisi oluşturmamak ve sadece ağız giriş şekillerinin etkisini incelemek amacıyla su alma ağızları tank tabanından ve yan duvardan yeterince uzak mesafede tankın merkezine yerleştirilmiştir (su alma ağızlarının tank tabanına ve yan duvarlarına olan mesafesi $S_{c}$ 'den oldukça büyüktür) $[8,9]$. Tüm ağızların tankın tabanına olan mesafesi $50 \mathrm{~cm}$ 'dir. Kullanılan farklı giriş ağızlarına ait hidrolik yarıçap aralığ 1 ise $R_{h}=0,887 \mathrm{~cm}-2,821 \mathrm{~cm}$ arasında değişim göstermektedir.

Su alma ağzı merkeze yerleştirildikten sonra tankın içerisi, kritik batıklığın çok üzerinde bir değere kadar şehir şebekesinden gelen suyla doldurulmuştur. Çevrintiyi oluşturacak debi vana yardımıyla ayarlanmış ve hava girişli çevrintinin oluşması için 1-2 saat beklenmiştir. Hava girişli çevrinti oluşmadığ takdirde tankın tabanında bulunan drenaj vanası bir miktar açılarak batıklık düşürülmüştür. Bu adımlar hava girişli çevrinti oluşuncaya kadar tekrarlanmıştır. Hava girişli çevrinti oluştuğunda su yüzü ve savak ölçümleri alınmıştır. Bu adımlar farklı giriş ağızları ve farklı debiler için tekrarlanmıştır. Deney sonuçları Şekil 69'da gösterilmiştir. 


\section{DENEY SONUÇLARININ DEĞERLENDİRILMESİ (EVALUATION OF EXPERIMENTAL RESULTS)}

Su alma ağzı giriş şeklinin kritik batıklık veya hava girişli çevrinti oluşumu üzerindeki etkisi iki temel nedene dayanır [23]. Bunlar aşağıda açıklanmıştır.

a) Hız dağılımı etkisi: Su alma ağzı giriş şekli, ağız girişindeki ve dolayısıyla da ağzın bulunduğu akım ortamındaki hız dağılımını etkiler. Su alma ağzı giriş şekli, ağza doğru gelişen akım ortamındaki her derinlikte en büyük hızların teğet olduğu devamlı akım çizgisinin (continuous streamline of the maximum velocities) yerini ve bu hızların büyüklüğünü belirleyeceğinden serbest yüzeyde oluşan çevrinti üzerinde etkilidir. Serbest yüzeydeki çevrintinin gelişimi esnasında; yüzeydeki akışkan taneleri arasında ağza doğru en büyük hıza sahip olan tane (ki bu tane yukarıda belirtilen en büyük hızların teğet olduğu devamlı akım çizgisi üzerindedir) viskozite nedeniyle o seviyede bulunan diğer komşu akışkan tanelerini de beraberinde sürükleyerek yüzeyde bir çöküntü oluşmasına neden olur. Yüzeydeki rahatsızlıklar, akışkan tanelerinin birbirleriyle çarpışmaları ve Dünya'nın dönüşünden kaynaklanan Coriolis etkisi sebebiyle, oluşan çöküntü ağza doğru hızını arttırarak ilerlerken aynı zamanda da döner. Bu çöküntü çevre sıvısı ile yeterince doldurulabilirse çevrinti daha da gelişip ağza hava giremez. Ancak çöküntü çevre sıvısı ile doldurulamıyorsa, ağza sıvı ile beraber hava da girmeye başlar. Ağız giriş şekli, oluşan çöküntünün yerini, şeklini (ne kadar derin veya geniş olacağını) belirler. Çöküntünün kaynağı olan en büyük hızların teğet olduğu devamlı akım çizgisinin varlığı (veya oluşumu) ağız giriş şeklinden bağımsızdır. Herhangi bir ağız giriş şekli için her derinlikte ağza doğru en büyük hızların teğetlerini birleştiren tek bir devamlı akım çizgisi vardır.

b) Havalı çevrintinin oluşumuna katkı yapan ağız debisi (Çevrintiyi besleyen ağız debisi etkisi): Hava girişli çevrinti oluşması için gerekli olan vortisitenin (veya sirkülasyonun) şiddeti, ağız giriş şekline bağlı olarak, ne kadarlık bir ağız debisinin hava girişine neden olan bu çevrintiye katkı yaptığıyla ilgilidir. Yüzeydeki her bir akışkan tanesi er ya da geç hava girişli çevrintiyi oluşturan ana burgulu akıma katılır. Bu katılım sırasında her bir yüzey tanesi bulunduğu konumda mevcut olan rahatsızlıkları da ana burgulu akıma taşır. Bu yüzden sirkülasyon şiddeti yüzeyden ağza doğru gittikçe artmaktadır [24]. Aynı zamanda yüzey veya yüzey altı akışkan taneleri bu ana burgulu akıma ne kadar erken (veya ağza ait düşey eksene göre ne kadar membadan) katılırlarsa hava girişli çevrinti oluşumuna o kadar katkı yaparlar. Ağız giriş şekli de akışkan tanelerinin bu ana burgulu akıma katılım biçimlerini etkilediğinden kritik batıklığı değiştirebilir.

Şekil 6-8`de sırasıyla $A=40 \mathrm{~cm}^{2}$ ve $A=100 \mathrm{~cm}^{2}$ 'lik alanlara sahip 6 farklı giriş geometrisine sahip ağızların boyutsuz kritik batıklıklarının $\left[S_{c} /\left(4 R_{h}\right)\right] \mathrm{F}, \mathrm{R}_{\mathrm{e}}$ ve W sayılarıyla değişimleri gösterilmiştir. $\mathrm{Bu}$ şekillerden de görüldügü üzere ağız giriş geometrisinin kritik batıklık üzerinde bir boyut etkisine sahip olduğu söylenebilir. Özellikle bu etki yüksek debilerde (veya yüksek Froude sayılarında) daha fazla hissedilirken Reynolds ve Weber sayılarında daha az hissedilmektedir. Bu durum diğer araştırmacıların da bildirdiği gibi belli Reynolds ve Weber sayılarından sonra bu sayıların kritik batıklık üzerinde etkilerinin ihmal edilebileceği tespiti ile paralellik göstermektedir. Ancak Şekil 6'dan anlaşılacağ üzere, model ile prototip su alma ağızları arasında Froude sayısı benzerliği kullanılırsa kritik batıklık açısından tam benzeşimin sağlanamayacağ 1 ve ihmal edilemeyecek bir ölçek veya boyut etkisi olduğu da görülmüştür. Şekil 6-8'de $A=100 \mathrm{~cm}^{2}$ lik ağızlar ile yapılan deneylerde, deney koşullarındaki sınırlamalar dolayısıyla elde edilebilen en büyük $\mathrm{F}, \mathrm{R}_{\mathrm{e}}$ ve $\mathrm{W}$ sayıları sırasıyla yaklaşık olarak 2, 200000 ve 5000 civarında olmuştur. $A=100 \mathrm{~cm}^{2}$ 'lik ağızlar için bu değerlerden daha büyük değerlerin olduğu bölge hakkında kesin yorum yapmak doğru olmayacaktır. Ancak bu bölgedeki davranışın $A=40 \mathrm{~cm}^{2}$ 'lik ağızların bu bölgedeki davranışına benzeyeceği beklenebilir. 

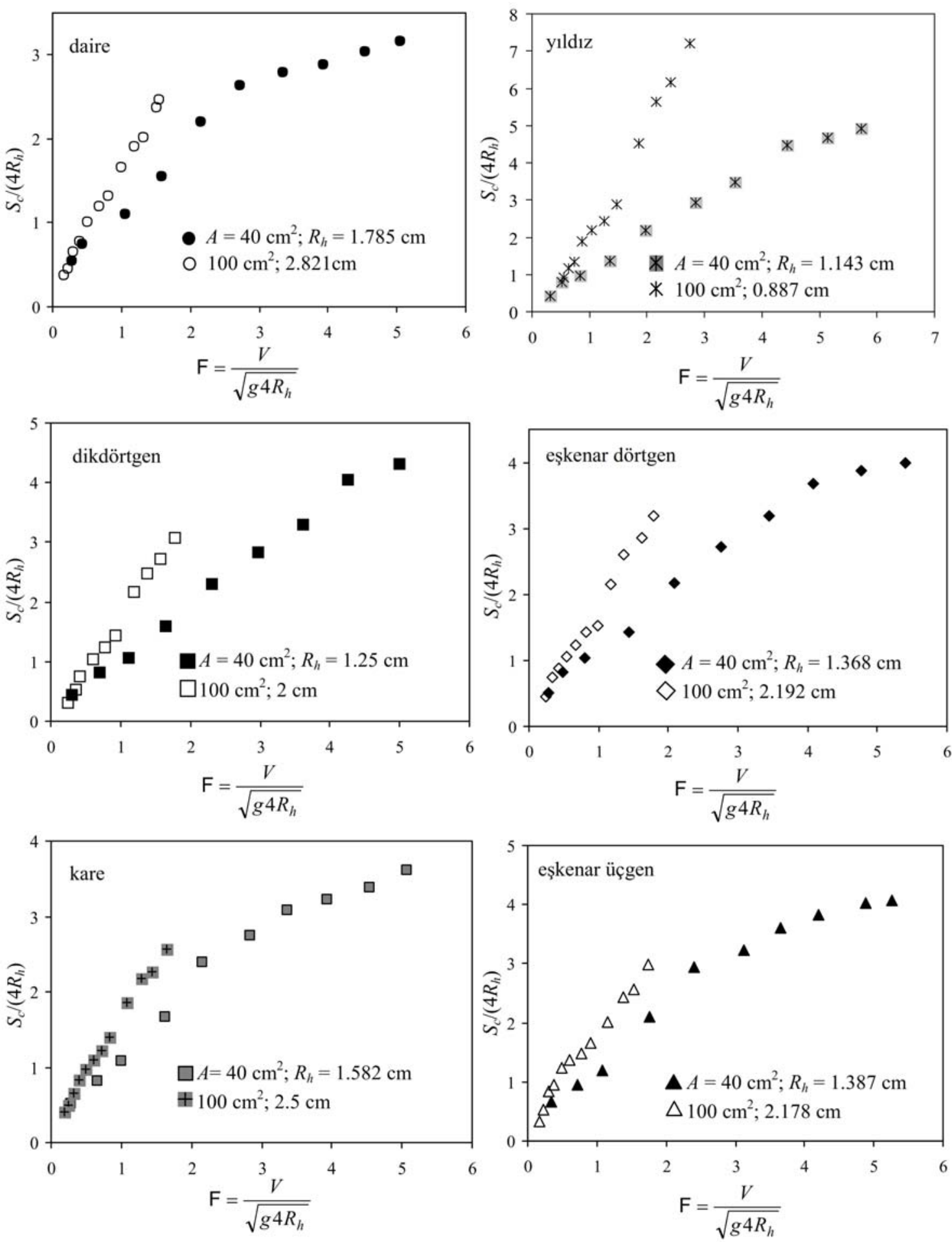

Şekil 6. Su alma yapısına ait Froude sayısı, $F$, ile $S_{d}\left(4 R_{h}\right)$ arasındaki ilişki 

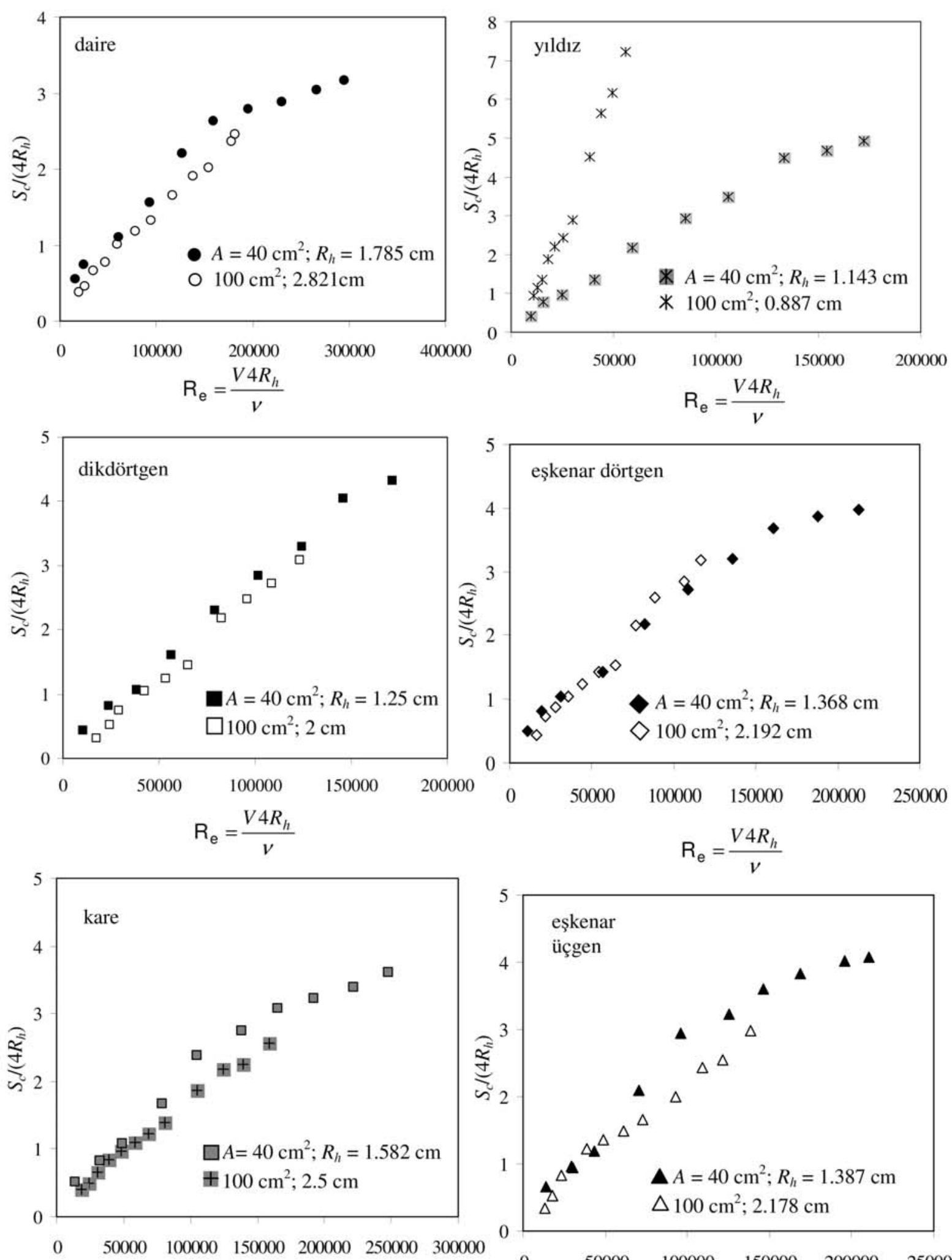

$\mathrm{R}_{\mathrm{e}}=\frac{V 4 R_{h}}{v}$

$$
\mathrm{R}_{\mathrm{e}}=\frac{V 4 R_{h}}{v}
$$

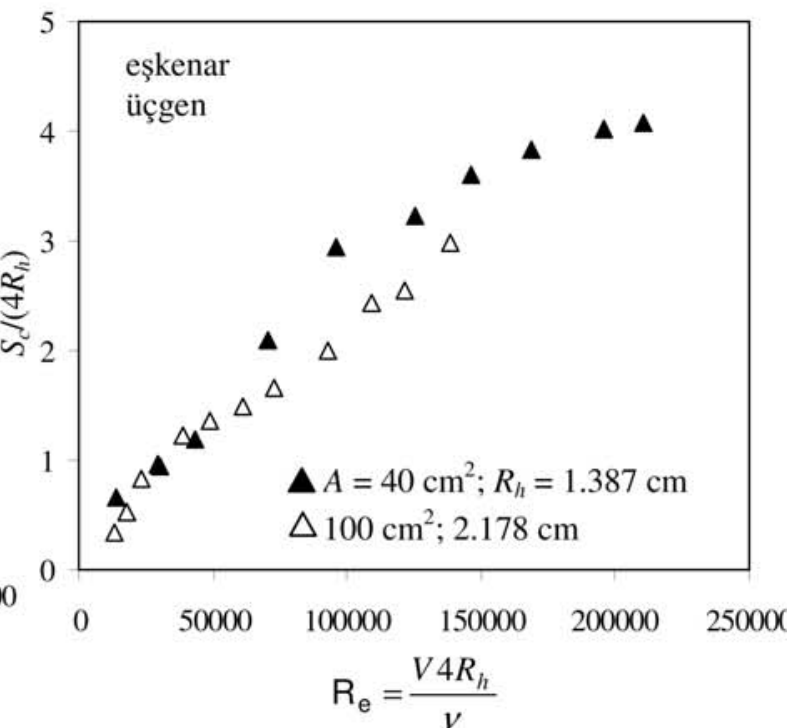

Şekil 7. Su alma yapısına ait Reynolds sayısı, $R_{e}$, ile $S_{c} /\left(4 R_{h}\right)$ arasındaki ilişki 

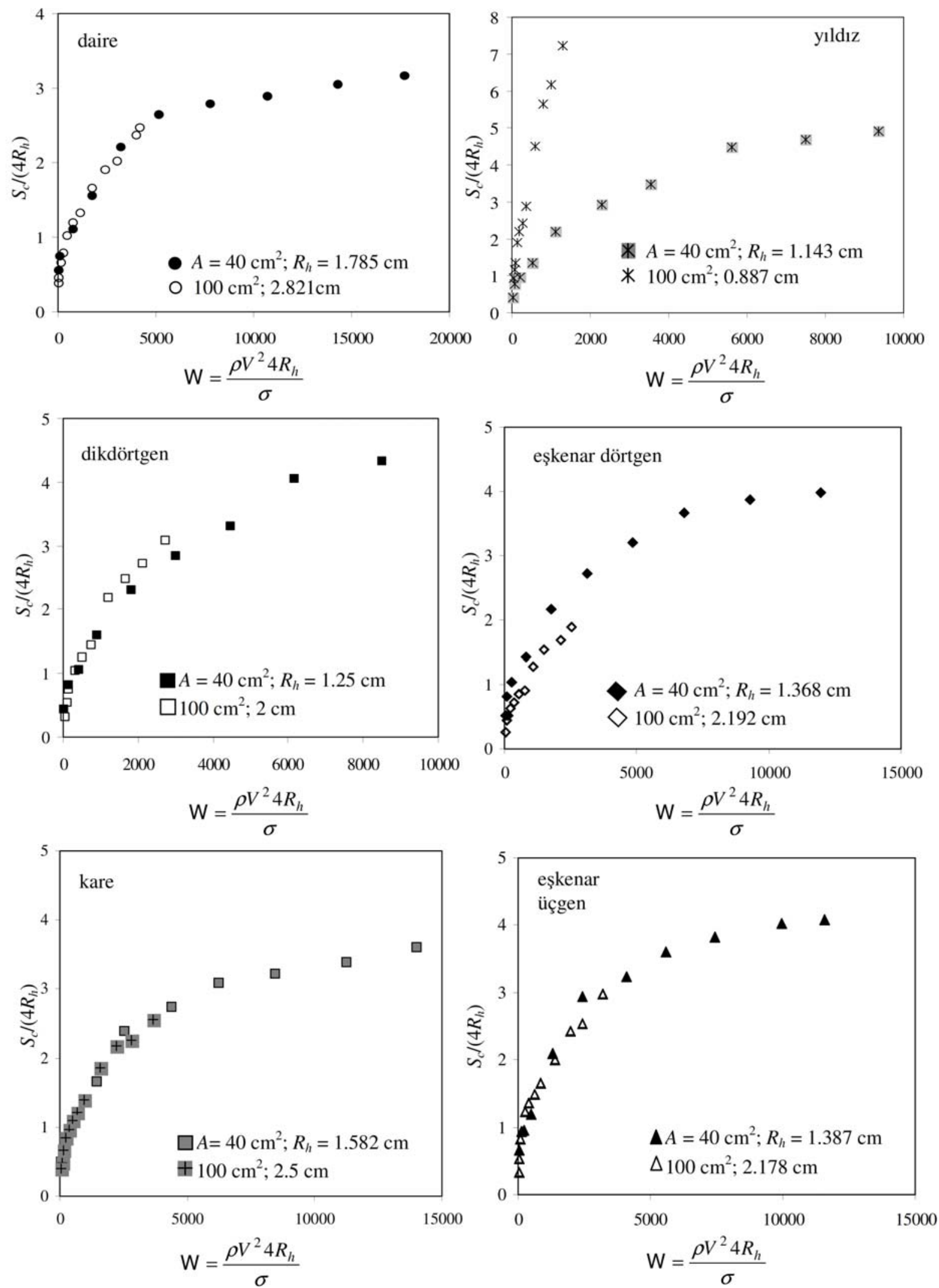

Şekil 8. Su alma yapısına ait Weber sayısı, $W$, ile $S_{d} /\left(4 R_{h}\right)$ arasındaki ilişki 

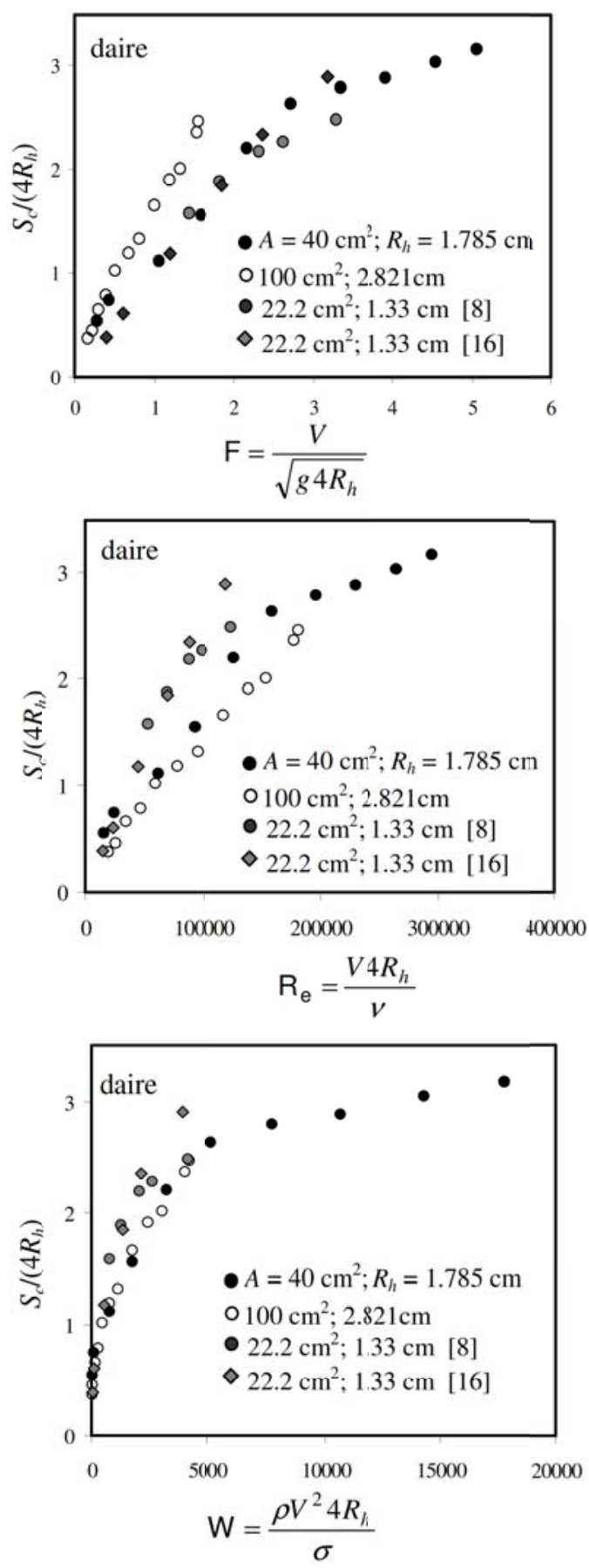

Şekil 9. Dairesel su alma yapısına ait deney sonuçlarının mevcut çalışmalarla karşılaştırılması

Mevcut çalışmalarla bu çalışma arasında sadece bir kıyas yapmak amacıyla Yıldırım ve Kocabaş [7] ve Taştan ve Yıldırım'ın [13] dairesel su alma ağızlarıyla durgun su ortamında elde ettiği neticeler Şekil 9'da gösterilmiştir. $\mathrm{Bu}$ araştırmacıların kullandıkları boru çapı $5,32 \mathrm{~cm}\left(A=22,2 \mathrm{~cm}^{2}\right)$ olup kanal tabanı ile ağız merkezi arasındaki düşey mesafe $21,28 \mathrm{~cm}$ 'dir. Görüldüğü gibi bu çalışmadaki deneylerle literatürdeki benzer çalışmaların sonuçları uyum içerisindedir. Bu çalışmada kullanılan diğer ağız şekilleriyle ilgili literatürde herhangi bir çalışma olmadığından sadece dairesel ağza ait sonuçlar kıyaslanmıştır. 


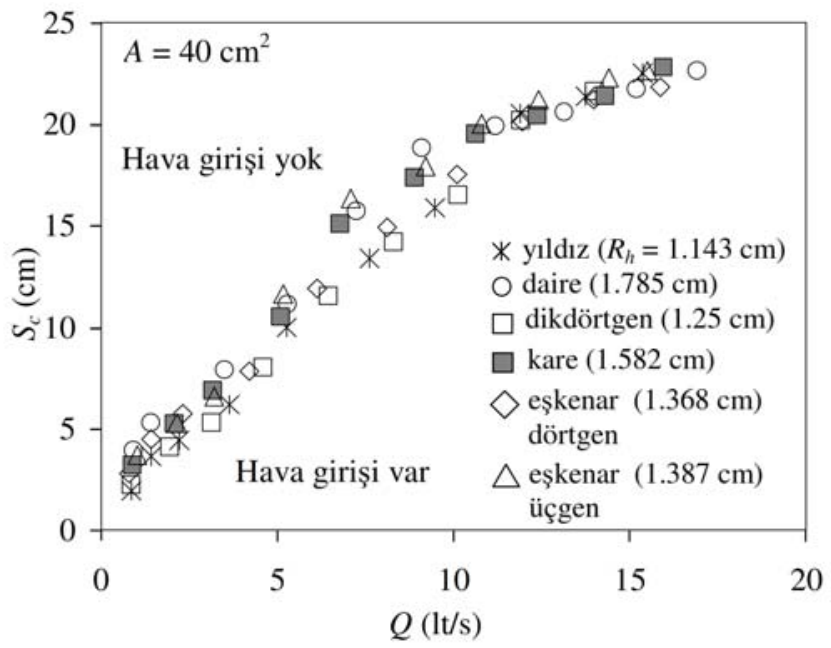

(a)

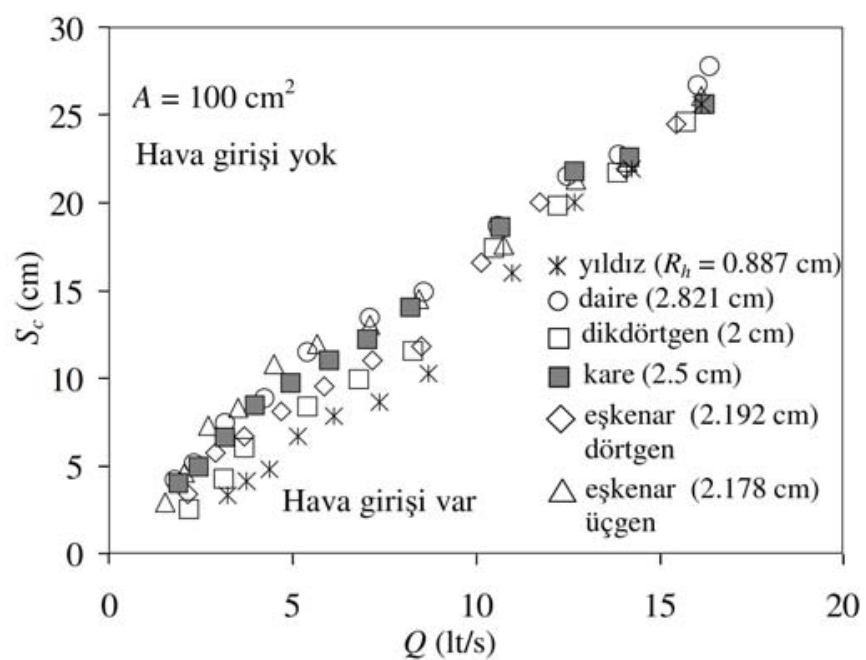

(b)

Şekil 10. Kritik batıklık ile ağız debisi, $Q$, arasındaki ilişki: a) $A=40 \mathrm{~cm}^{2}$, b) $A=100 \mathrm{~cm}^{2}$

Şekil 10'da sırasıyla $A=40 \mathrm{~cm}^{2}$ ve $A=100 \mathrm{~cm}^{2}$ 'lik alanlara sahip 6 farklı giriş geometrisine sahip ağızların kritik batıklıklarının ağız debisiyle değişimleri görülmektedir. Bu şekilden de anlaşılacağı üzere incelenen debi aralığı göz önüne alındığında özellikle yüksek debilerde ağız giriş geometrisinin kritik batıklık üzerinde etkisinin çok olmadığ 1 ancak ağız debisi düştükçe ağız giriş şeklinin kritik batıklık üzerinde etkisinin arttığı görülmüştür. Daha önce anlatıldığg gibi ağız giriş şekli hava girişli çevrinti oluşumu üzerinde; hız dağılımı etkisi ve çevrintiyi besleyen ağız debisi etkisi olmak üzere iki etkiye sahiptir. Dairesel kesite sahip ağza olan akım noktasal kuyu karakterli olduğundan ağza giren tüm akım ana burgulu akıma katkı verir. Öte yandan, dairesel kesite sahip ağız hidrolikçe en uygun ağız şekli olduğundan kesiti boyunca hız dağılımı üniform dağılıma oldukça yakındır (cidar yakınlarındaki hızın merkezdeki hızdan küçük olmasına rağmen). Dolayısıyla sıvı yüzeyinde ağız merkezinin üzerinde çöküntü oluşmasına neden olan en büyük hızın büyüklügü de nispeten daha az olur. Dairesel kesitli olmayan ağızlarda $R_{h}$ azaldıkça (AAGÇ arttıkça) ana burgulu akıma katkı yapan ağız debisi payı azalırken, ağız kesiti boyunca hız dağılımı üniform olmaktan uzaklaşır. Bu ağızlarda merkezdeki hız cidar yakınlarındaki hıza göre çok daha büyük olur. Dolayısıyla yukarıda açıklanan çevri oluşumu açısından iki etki birbiriyle ters yönde çalışır (çevriyi besleyen ağız debisi etkisi arttıkça, hız dağılımı etkisi azalır). Şekil 6-8'den de görüleceği üzere örneğin $A=40 \mathrm{~cm}^{2}$ 'lik ağız için $\mathrm{F}<3, \mathrm{R}_{\mathrm{e}}<5 \times 10^{4}$ ve $\mathrm{W}<2 \times 10^{3}$ durumunda bu iki etki birbirlerini yaklaşı olarak dengelemektedirler. 


\section{SONUÇLAR (CONCLUSIONS)}

Bu çalışmada su alma ağzı giriş şeklinin ağza ait kritik batıklık üzerindeki boyut etkisi araştırılmıştır. İncelenen konunun doğası gereği teorik analiz çok güç olduğundan boyut analizi neticesinde bulunan boyutsuz parametreler arasındaki ilişki, deneyler yapılarak elde edilmeye çalışılmıştır. Deneylerde laboratuar ve kullanılan deney düzeneğinin de kısıtlamaları düşünülerek $40 \mathrm{~cm}^{2}$ ve $100 \mathrm{~cm}^{2}$ iç kesit alanlarına ve altı farklı kesit şekline sahip su alma ağızları kullanılmıştır. Deneylerde akım sınırlarından kaynaklanan herhangi bir engel veya sürtünme etkisi olmaması için ağız, silindirik tankın tabanından ve yan duvarından oldukça uzağa ve tank merkezine yerleştirilmiştir. Deneyler sonucunda ağızlara ait kritik batıklığın ağız Froude, Reynolds ve Weber sayıları ile değişimleri incelenmiş olup aşağıda sıralanan sonuçlara ulaşılmıştır.

- Farklı giriş alanlarına ve çeşitli giriş geometrilerine sahip ağızların kritik batıklık açısından bir boyut etkisine sahip oldukları görülmüştür. Dolayısıyla her bir farklı ağız giriş geometrisi ve akım şartı, kritik batıklık açısından kendine özgü özellikler taşır. Froude sayısı benzeşimine göre kurulacak modeller kritik batıklık açısından tam bir benzeşim sağlayamaz.

- Ağız debisine bağlı olarak ağız giriş şeklinin, aynı iç kesit alanına ve faklı giriş geometrilerine sahip ağızların kritik batıklığı üzerinde bir miktar etkisi vardır. Bu çalışmada incelenen debi aralığı göz önüne alındığında özellikle düşük debilerde ağız giriş geometrisinin kritik batıklık üzerinde etkisinin yüksek debilere göre daha fazla olduğu görülmüştür.

- İleride yapılacak çalışmalarda daha farklı ağız şekilleri ve daha farklı ağız kesit alanları kullanılarak genel ifadeler aranmasının faydalı olacağı düşünülmektedir.

\section{SİMGELER (SYMBOLS)}

$A=$ ağzın kesit alanı

$b=$ su alma ağzı ile silindir tankın yanal duvarı arasındaki mesafe

$c=$ su alma ağzı merkeziyle silindir tankın tabanı arasındaki mesafe

$D=$ dairesel kesitli su alma ağzı iç çapı

$\mathrm{F}=\mathrm{su}$ alma yapısına ait Froude sayıs

$g=$ yerçekimi ivmesi

$\mathrm{K}=$ çevrinti sayısı

$Q=$ ağız debisi

$\mathrm{R}_{\mathrm{e}}=$ su alma yapısina ait Reynolds sayıs1

$R_{h}=$ hidrolik yarıçap

$S=$ batıklı

$S_{c}=$ kritik batıklı

$V=$ su alma yapısındaki ortalama akım hız

$\mathrm{W}=$ su alma yapısına ait Weber sayıs 1

$\Gamma=$ akıma dışardan uygulanan çevrinti

$\rho=$ akışkanın yoğunluğu

$\sigma=$ yüzey gerilmesi

$v=$ kinematik viskozite 


\section{KAYNAKLAR (REFERENCES)}

[1] L. L. Daggett, G. H. Keulegan, Similitude in free-surface vortex formations. Journal of Hydraulic Division (ASCE), 100:11 (1974) 1565-1581.

[2] A. K. Jain, K. G. Ranga Raju, R.J. Garde, Vortex formation at vertical pipe intakes. Journal of Hydraulic Division (ASCE), 104:10 (1978) 1429-1448.

[3] H. O. Anwar, M. B. Amphlett, Vortices at vertically inverted intake. Journal of Hydraulic Research, $18: 2(1980)$ 123-134.

[4] G. E. Hecker, Model-Prototype comparison of free surface vortices. Journal of Hydraulic Division (ASCE), 107:10 (1981) 1243-1259.

[5] N. Yıldırım, F. Kocabaş, Critical submergence for intakes in open channel flow. Journal of Hydraulic Engineering, 121:12 (1995) 900-905.

[6] K. Taştan, Çoklu Su alma ağızları için kritik batıklı̆̆ın süperpozisyon yöntemiyle hesabı. Yüksek Lisans Tezi, Gazi Üniversitesi Fen Bilimleri Enstitüsü, Ankara, 2007.

[7] N. Yıldırım, F. Kocabaş, Critical submergence for intakes in still-water reservoir. Journal of Hydraulic Engineering, 124:1 (1998) 103-104.

[8] N. Yıldırım, F. Kocabaş, S. C. Gülcan, Flow-boundary effects on critical submergence of intake pipe. Journal of Hydraulic Engineering, 126:4 (2000) 288-297.

[9] N. Yıldırım, F. Kocabaş, S. C. Gülcan, Errata for Flow-boundary effects on critical submergence of intake pipe. Journal of Hydraulic Engineering, 133:4 (2007) 461.

[10] N. Y1ldırım, Critical submergence for a rectangular intake. Journal of Engineering Mechanics, $130: 10$ (2004) 1195-1210.

[11] N. Yıldırım, K. Taştan, Bir su alma ağzının kritik batıklığı üzerinde akım sınır etkilerinin karşılaştırılması. İ.M.O Teknik Dergi, 20:3 (2009) 4779-4792.

[12] K. Taştan, Su alma yapılarında oluşan havalı çevrintinin özellikleri. Doktora Tezi, Gazi Üniversitesi Fen Bilimleri Enstitüsü, Ankara, 2013.

[13] K. Taştan, N. Yıldırım, Effects of dimensionless parameters on air-entraining vortices. Journal of Hydraulic Research, 48:1 (2010) 57-64.

[14] F. Surich-Gulick, S. J Gaskin, M. Villeneuve, E. Parkinson, Free surface intake vortices: theoretical model and measurements. Journal of Hydraulic Research, 52:4 (2014) 502-512.

[15] K. Taştan, N. Yıldırım, Effects of Froude, Reynolds and Weber numbers on an air-entraining vortex. Journal of Hydraulic Research, 52:3 (2014) 421-425.

[16] K. Taştan, Scale and flow boundary effects for air-entraining vortices. Proceedings of Institution of Civil Engineers- Water Management, 170:4 (2017) 198-206.

[17] N. Eroğlu, T. Bahadırlı, Prediction of critical submergence for a rectangular intake. Journal of Energy Engineering, 133:2 (2007) 91-103.

[18] K. Taştan, Critical submergence for isolated and dual rectangular intakes. Sadhana, 41:4 (2016) 425433.

[19] J. Yang, L. Ting, A. Bottacin-Busolin, L. Chang, Effects of intake-entrance profiles on free-surface vortices. Journal of Hydraulic Research, 52:4 (2014) 523-531.

[20] D. F. Denny, An experimental study of air-entraining vortices in pump sumps. Proceedings of Institution of Mechanical Engineers, 170:2 (1956) 106-116. 
[21] A. K. Jain, Vortex formation at vertical pipe intakes. PhD Thesis. Department of Civil Engineering, University of Roorkee, India, 1977.

[22] F. Kocabaş, Geçirimsiz sınırların ve sirkülasyonun su alma ağzına ait kritik batıklığa etkisi. Doktora Tezi, Gazi Üniversitesi Fen Bilimleri Enstitüsü, Ankara, 1999.

[23] K. Taştan, N. Yıldırım, Effects of intake geometry on the occurrence of a free-surface vortex. Journal of Hydraulic Engineering, 144:4 (2018) 04018009.

[24] H. Sun, Y. Liu, Theoretical and experimental study on the vortex at hydraulic intakes. Journal of Hydraulic Research, 53:6 (2015) 787-796. 